\title{
CHATTERBLOCK ${ }^{\circledR}$ CONTROL: ELIMINATION OF MILL CHATTER VIBRATION IN COLD ROLLING*
}

\author{
Georg Keintzel ${ }^{1}$ \\ Christoph Pröll \\ Konrad Krimpelstätter ${ }^{3}$ \\ Gerlinde Djumlija ${ }^{4}$
}

\begin{abstract}
The origin and elimination of $3^{\text {rd }}$ octave mill chatter is a frequently investigated topic since tandem cold mills are in operation. So far only chatter monitoring systems have been successfully deployed, but this implies speed reductions and therefore a significant loss in mill output. Primetals Technologies has developed a new system using active injection of damping in order to eliminate $3^{\text {rd }}$ octave mill chatter. The new hydraulics-based ChatterBlock ${ }^{\circledR}$ Control has now been proven successfully in mill operation. $3^{\text {rd }}$ octave mill chatter, typically occurring in a frequency range between 90 and $150 \mathrm{~Hz}$, is a self-excited vibration phenomena typically occurring in the rear stands of tandem cold mills. It can produce significant gauge variations and even cause strip breaks. $3^{\text {rd }}$ octave mill chatter is characterized by a quickly diverging vertical vibration of the rolls for specific rolling conditions (material, mill speed, forces, gauge etc.). Its occurrence requires immediate speed reduction of the mill in order to avoid strip breakage and/or strip quality degradation. This phenomenon thus severely limits mill productivity. The first step to proof the industrial feasibility of the new system was its installation on stand no. 4 of a 5 -stand tandem mill. The development process and first results of the industrial implementation will be presented in this paper.
\end{abstract}

Keywords: Cold rolling; $3^{\text {rd }}$ octave chatter; Vibrations. 


\section{INTRODUCTION}

The tandem cold mill is currently running thin gauges at rather high rolling forces. Suddenly a loud noise starts, and the mill begins to vibrate violently - it is "chatter", more precisely and well known as $3^{\text {rd }}$ octave chatter.

Maybe you are lucky and you own a chatter detection system, which detects chatter in a very early stage and decreases the mill speed automatically. If not, you rely on the quick reaction of the operator and some good luck to avoid a serious strip break and potential equipment damage.

In any case you have to run the mill significantly slower compared to what the design of the mill would allow.

$3^{\text {rd }}$ octave chatter is a phenomenon common to practically all tandem cold mills; its occurrence depends on the specific production characteristics of a mill. Phenomenologically it is a quickly diverging vibration suddenly occurring at chatter critical materials as soon as a certain speed level is reached.

The most prominent drawback of $3^{\text {rd }}$ octave chatter is a severe speed limitation of a more or less large spectrum of your production. But dependent on the specific circumstances of your production, the potential occurrence of chatter negatively influences your production in various ways.

But, there is now a solution!

In a challenging project Primetals Technologies has developed a unique solution to eliminate $3^{\text {rd }}$ octave mill chatter. This unique solution "ChatterBlock ${ }^{\circledR}$ Control" has now been implemented the first time on an industrial cold mill.

A mill benefits in various ways from the installation of this system, most prominently a significant increase of production capacity. Figure 1 below lists some of the potential benefits.) and process-optimization systems (Level 2) for all casting and rolling operations.

\subsection{Customer Benefits}

- Rolling speed

The most obvious advantage is a significant increase of the rolling speed (target: maximum mill speed with chatter critical strips)

- Production

Higher production capacity (typical increase of up to 10\%)

- Strip breaks, damages in the mill

In case of chatter critical materials, mill operators often try to run the mill close to the limit where $3^{\text {rd }}$ octave chatter occurs (with a permanent danger of a strip break when chatter occurs). The ChatterBlock ${ }^{\circledR}$ Control stabilizes the stand, decreases the tendency for vibrations and therefore danger of strip breaks.

- Rolling process

Typical production constraints due to a possible chatter occurrence (e.g. lower strip tension to decrease chatter tendency, rerouting of chatter critical strips, more frequent roll changes) are no longer required. The rolling process thus is more stable and more flexible.

- Rolling parameter

This also allows a higher flexibility in choosing the rolling parameters (setup values) and allows a better optimization. 


\section{THE DEVELOPMENT}

\subsection{A Great Approach at the Beginning}

When the idea was born to find a solution that eliminates $3^{\text {rd }}$ octave chatter, nobody had an imagination what challenges will be encountered. Maybe different to most other approaches the starting point was not a pure mechanical point of view, utilizing even more complicated models of a mill stand. Initially the problem was analyzed from a control point of view, keeping the view across the disciplines - an ideal "mechatronic" approach.

It can be shown that the interaction of the elastic mill stand together with the strip under tension and the massflow can become unstable. It is a parameter induced instability (dependent on strip speed, tension, friction, roll force etc.). And the interesting thing is, that a mill stand can be broken down to a simple model (three masses, springs, a hydraulic cylinder and a linearized model of the strip) to show, that such a system can become unstable (cf. Figure 1).

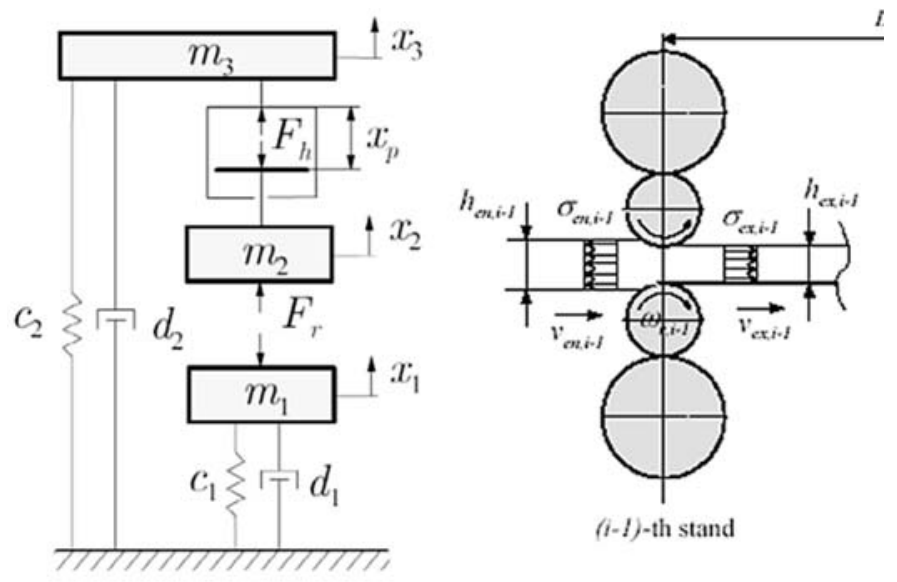

Figure 1. Simple model of a mill stand

In a classic scientific approach, the phenomenon was thus broken down to its very basic roots by eliminating the ballast of complicated mechanical model structures.

It could be shown, that the active injection of damping can stabilize the system. While control experts prefer to talk about the poles of the system in the right half-plane (in case of instability) mechanical experts like to look at it as a system where the damping becomes negative, causing a divergent vibration. In other words, it requires this differential amount of damping to eliminate the vibration, to bring the poles back to the left half-plane respectively.

One great feature of injecting damping via a controller is that you can "shape" the influence in many ways. It is of utmost importance that this system does not negatively influence the existing control, e.g. by damping the gauge controller activity as it would be the case with a mechanical damper. Therefore filters are used to achieve a clear frequency separation between a gauge controller (being active approx. up to $20 \mathrm{~Hz}$ ) and the system being active in a small band around the chatter frequency (e.g. $120 \mathrm{~Hz}$ ) (cf. Figure 2). 


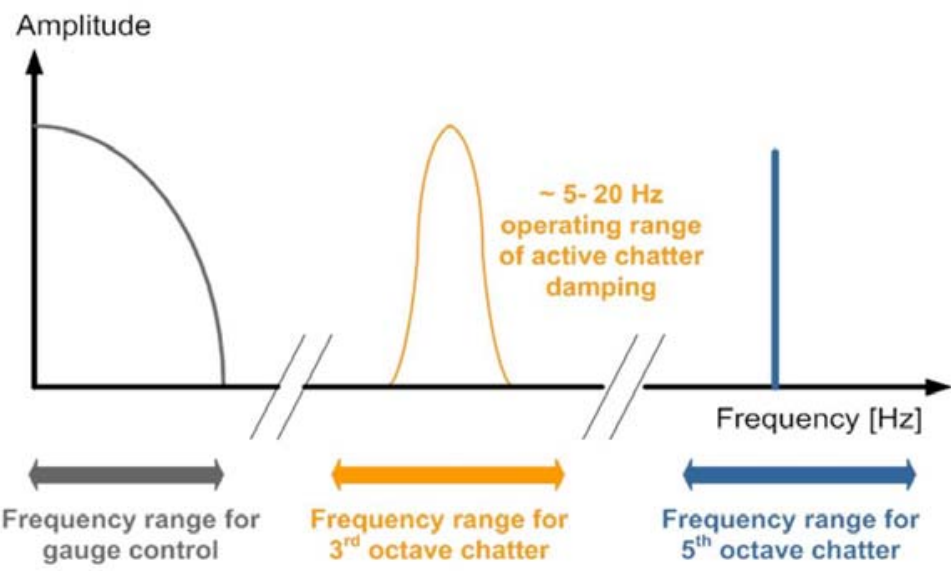

Figure 2. Frequency separation - a clear separation of the activity of the ChatterBlock ${ }^{\circledR}$ Control versus an HGC

This theoretical but fundamental basis was the starting point to proceed step by step to a reliable industrial system adding complexity and facing numerous challenges.

\subsection{Laboratory Investigations}

It was finally decided to use a hydraulic actuator. Hydraulics, after all, seemed to be the most promising approach compared with other principles (mechanical, piezoelectric, etc.). The first big challenge was actually the hydraulic valve. As chatter occurs, very generally spoken, in a frequency range of $90 \mathrm{~Hz}$ to $150 \mathrm{~Hz}$, and as such a valve is part of a closed loop controller, a very fast servo valve with very little phase shift (a few 10 degrees) was required. Generally large servo valves are multistage valves, which exhibit an extreme phase shift at higher frequencies, especially above $100 \mathrm{~Hz}$. There was no valve existing on the market that fulfilled the requirements. Finally with MOOG GmbH (a leading producer of high performance servo valves for the metal industry) a partner was found to develop together a valve that fulfilled the requirements (cf. Figure 3).

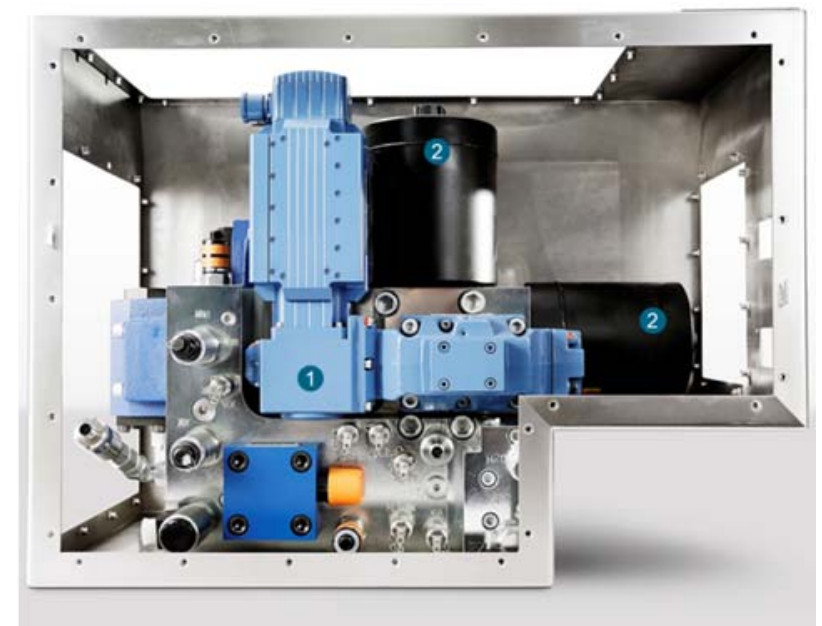

Figure 3. The unique Moog servo valve, mounted on the valve block

The next challenge was to integrate this valve in a hydraulic circuit. In the range of $3^{\text {rd }}$ octave chatter (above $100 \mathrm{~Hz}$ ) wave phenomena become important in hydraulic circuits and it became clear that there is only few knowledge on this field worldwide. 
In cooperation with the Johannes Kepler University in Linz the development of an appropriate hydraulic design that works well at high frequencies was initiated. In parallel a hydraulic test stand at the university was installed, which proved to be very helpful. Hydraulic cylinders (half the size of real "HGC" cylinder) were used and hydraulic effects could be very realistically analyzed.

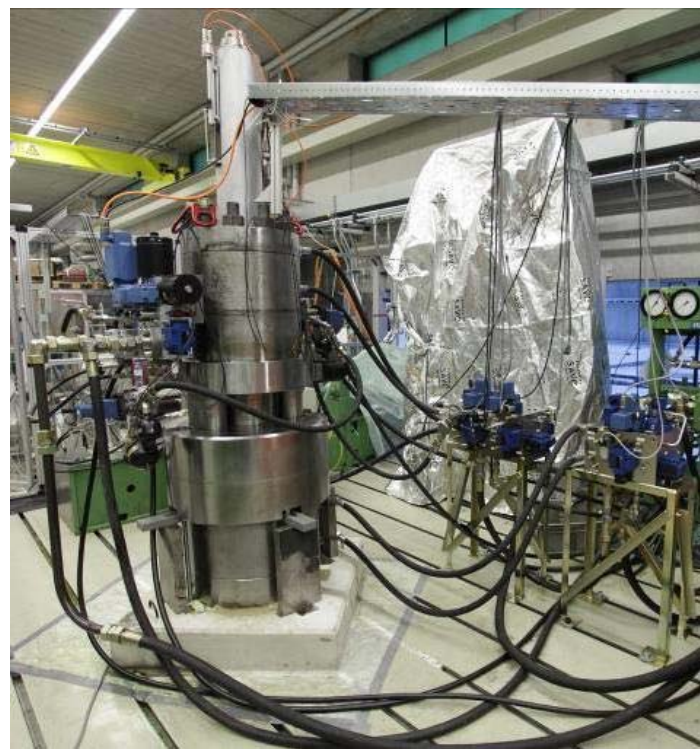

Figure 4. Hydraulic test stand at the Johannes Kepler University in Linz/Austria

A destabilized hydraulic system can be simulated with this test stand and it can be shown that the injection of damping stabilizes this system. All these tests brought important insights and finally the confidence to install the system in a real rolling mill.

\subsection{The industrial Concept}

Being aware, that this phenomenon is in principle immanent to all tandem cold mills (and even other mills), the target for the product design was a mechatronic system with an interface structure as clear and simple as possible to fit in practically all tandem mills, and certainly to be a modular part of Primetals Technologies mill design.

To install the system in any mill it requires following modifications (individual adaptations are certainly possible)

- Modification of the existing HGC cylinders for mounting a new valve block

- Attach the system to the existing hydraulic pump system. As an existing hydraulic system typically is designed for a quick roll change (movement of an HGC cylinder of several $\mathrm{mm} / \mathrm{s}$ ), the ChatterBlock ${ }^{\circledR}$ Control, working only during rolling, should have sufficient energy from the existing hydraulic pump system

- Installation of two acceleration sensors (one on the cylinder housing, one on the piston)

- Installation of two electric cabinets (sensor interfaces, and converter for the directly driven valve) on the stand (two other cabinets in an automation room)

- Interface to the existing automation: the system basically works independently, therefore a minimum interface is required (like an interface to a safety PLC "emergency off", and a communication to the existing automation system, configurable, minimum on/off switch). 
Figure 5 illustrates this concept graphically.

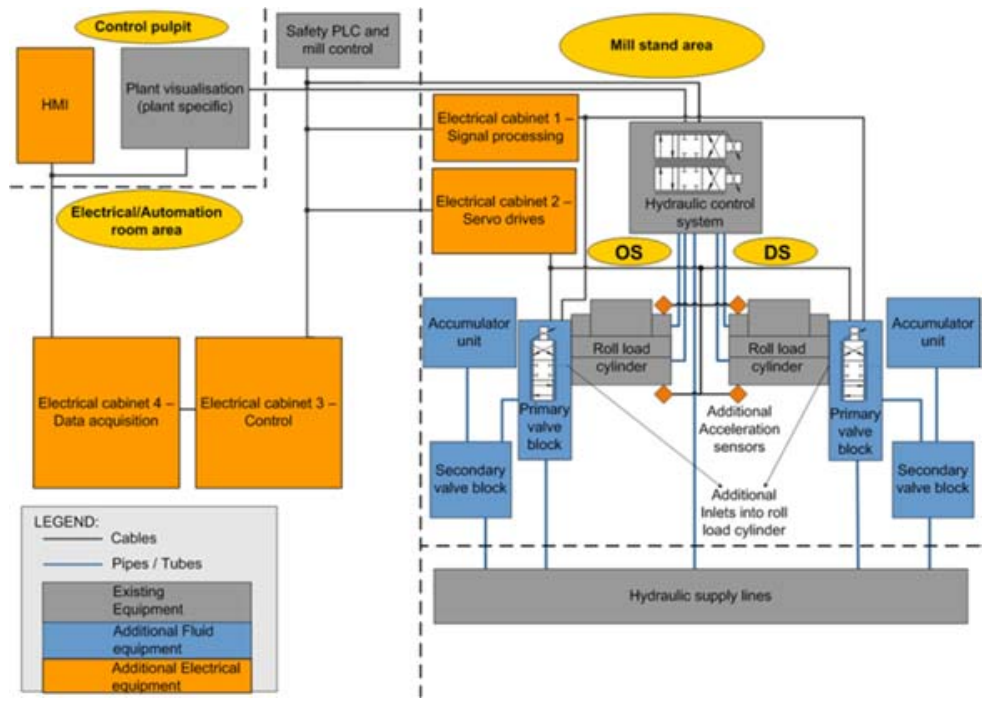

Figure 5. Overall implementation concept

\subsection{First Installation at NLMK/Russia}

The system was then ready to be tested on an industrial cold rolling mill, as the functionality could only be proven in a real mill, where $3^{\text {rd }}$ octave chatter actually occurs. With NLMK, one of the leading steel producers in Russia was found as a partner who was very interested in the system and very open to take the risk and challenge of such a new innovative step.

The idea was to install the new system in a first step on stand 4 of the 5 stand continuous tandem cold mill. This mill was built in the early 1980ies and has a significant amount of $3^{\text {rd }}$ octave chatter critical products nowadays. Stand 4 is the most chatter prone stand. After successful installation on stand 4 further installations are planned on stand 3 and 5 .

The first step was to modify two of the spare HGC cylinders and to renew the cylinders at this occasion. Before the cylinders were sent back to Russia, a factory integration test with the whole equipment was performed to ensure a quick and smooth installation in the mill (cf. Figure 6).

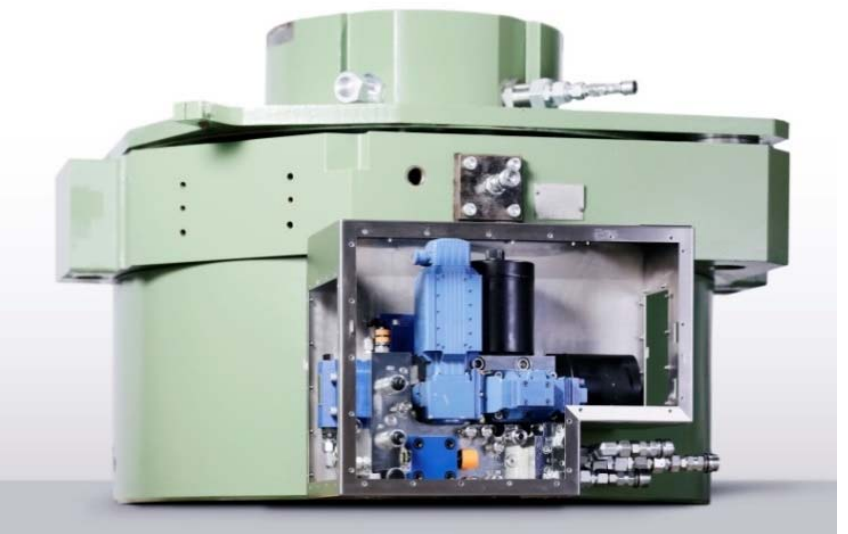

Figure 6. The revamped cylinder with the attached (chatter) valve block 
To minimize downtimes the installation was done in three steps during the normal planned mill shutdowns.

- Installation of electric cabinets and the measurement system

- Change of the HGC cylinders and installation of the modified cylinders

- Hydraulic piping, start of commissioning

Commissioning started very well, due to the pretesting of the system, and a professional and efficient installation organized by NLMK and assisted by Primetals Technologies. The first few weeks were full with new experiences and optimizations of the system. With the first chatter critical strips the tuning of the parameters of the controller was started cautiously and the injection of damping was increased. The ultimate first goal was to show the effectiveness of the physical principle - the stabilization of the stand by active injection of damping.

At one instance, while the system was active and a chatter critical strip was rolled (at a higher speed as usual) the system was switched off.

Immediately the stand started to vibrate and the operator had to quickly react by reducing the mill speed to stabilize the stand. A perfect proof for the functionality of the system (cf. Figure 7)!

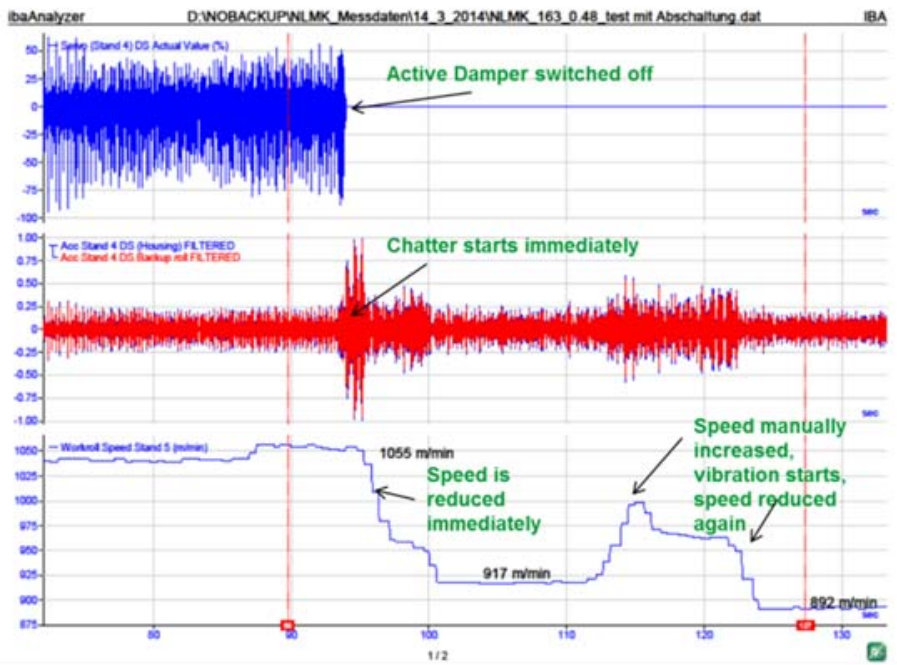

Figure 7. The proof of the functionality of the system

Beside several practical optimizations of the system and other typical commissioning requisites the main goal for the first commissioning phase was to proof the functionality of the system and to start to analyze the parameter variability (notably the vibration characteristics) over the production range and equipment variability (roll sets) as a basis for a subsequent optimization of system parameters and functionality to ensure a stable operation over the whole critical product range.

Therefore in this initial phase the speed increase with the system was limited to moderate speed rises also for production reasons. Critical strips rolled in this phase with an initial parameter set for the system showed consequently a clear reduction of the overall vibration level and the rolling speed was significantly increased (without deliberately pushing the speed to its limits).

A first test, demonstrating the current performance of the system was carried out in December 2014. During this test, the functionality could reproducibly be shown.

Figure 8 shows a typical example of two strips rolled during this test. With active ChatterBlock ${ }^{\circledR}$ Control, the strip could be rolled in this case with maximum mill speed $(1450 \mathrm{~m} / \mathrm{min})$ without any occurrence of chatter. Without active ChatterBlock ${ }^{\circledR}$ Control, 
the operator tried several times to increase the speed, but chatter occurred each time. Again a clear proof of the functionality of the system

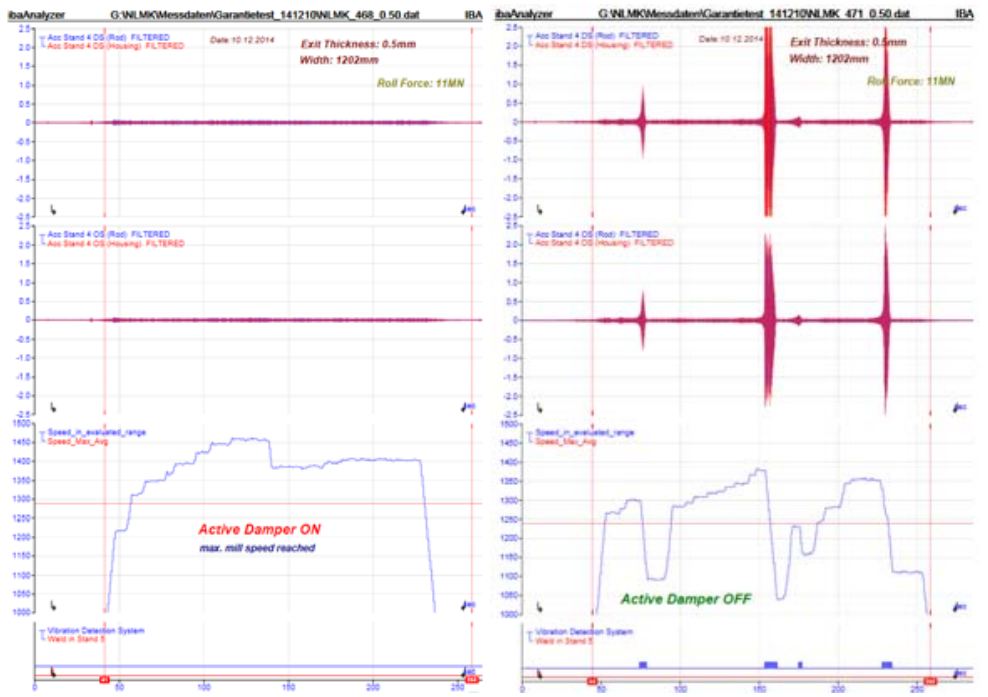

Figure 8. Comparision of two strips, one rolled with, the other without ChatterBlock ${ }^{\circledR}$ Control

This first test though was performed without finally required minor mechanical optimizations Notably, a problem are contact elasticities due to suboptimal contact areas in the roll force path, which are low dampened (causing higher vibration amplitudes, decoupling masses thus generating new resonances), and which significantly reduce the efficiency of the installed system. Furthermore a bunch of parasitic resonance frequencies neighboring the chatter frequencies are challenging requiring the design of sophisticated signal shaping in the frequency domain to ensure, that the system solely reacts on chatter occurrences. These are the next steps planned to finally optimize the system.

\section{CONCLUSION}

The first industrial installation impressively demonstrated the functionality of the concept of stabilizing the mill stand by active injection of damping. This was possible due to the support of the great project team of NLMK and the staff of the NLMK 2030 tandem mill. Next task is to optimize the various parameters of the system across the whole chatter critical material range and to do further mechanical mill optimizations to fully utilize the capability of the ChatterBlock ${ }^{\circledR}$ Control. 